\title{
Research and Analysis of Permanent Magnet Transmission System Controls on Diesel Railway Vehicles
}

\author{
Lili Kang ${ }^{1,2}$, Dongjie Jiang ${ }^{2}$, Chaoying Xia ${ }^{1, *}$, Yongjiu $\mathrm{Xu}^{2}$ and Kaiyi Sun ${ }^{2}$ \\ 1 School of Electrical and Information Engineering, Tianjin University, Tianjin 300072, China; \\ kanglili0501@163.com \\ 2 CRRC Tangshan Co., Ltd., Tangshan 064000, China; sjc-jiangdongjie@tangche.com (D.J.); \\ xuyongjiu.ts@crrcgc.cc (Y.X.); sjc-sunkaiyi@tangche.com (K.S.) \\ * Correspondence: xiachaoying@126.com
}

Citation: Kang, L.; Jiang, D.; Xia, C.; Xu, Y.; Sun, K. Research and Analysis of Permanent Magnet Transmission System Controls on Diesel Railway Vehicles. Electronics 2021, 10, 173. https://doi.org/10.3390/ electronics10020173

Received: 11 November 2020 Accepted: 30 December 2020 Published: 14 January 2021

Publisher's Note: MDPI stays neutral with regard to jurisdictional clai$\mathrm{ms}$ in published maps and institutional affiliations.

Copyright: (C) 2021 by the authors. Licensee MDPI, Basel, Switzerland. This article is an open access article distributed under the terms and conditions of the Creative Commons Attribution (CC BY) license (https:// creativecommons.org/licenses/by/ $4.0 /)$.

\begin{abstract}
As the energy crisis and environmental pollution continue to be a gradual threat, the energy saving of transmission systems has become the focus of railway vehicle research and design. Due to their high-power density and efficiency features, permanent magnet synchronous motors (PMSM) have been gradually applied in railway vehicles. To improve the efficiency of the transmission system of diesel railway vehicles, it is a good option to use PMSM as both a generator and traction motor to construct a full permanent magnet transmission system (FPMTS). Due to the application of the new FPMTS, some of the original control strategies for diesel railway vehicle transmission systems are no longer applicable. Therefore, it is necessary to adjust and improve the control strategies to meet the needs of FPMTS. We studied several key issues that affect the reliability and comfort of the vehicles. As such, this paper introduced the FPMTS control strategy, including the coordinated control strategy of the diesel and the traction motor, the two degrees of freedom (2DOF) decoupling current regulator, the maximum torque control of the standardized unit current, the wheel slip protection control, and the fault protection strategy. The experiment was carried out on the test platform and the test run of the diesel shunting locomotive equipped with the FPMTS. The results showed that the control strategy described in this paper met the operation characteristics of the FPMTS and that the control performance was superior. The study of FPMTS lays the foundation for the subsequent application of permanent magnet motors in high-powered diesel locomotives and high-speed diesel multi-units.
\end{abstract}

Keywords: diesel transmission system; permanent magnet synchronous motor (PMSM); two degrees of freedom (2DOF); maximum torque control; railway vehicles

\section{Introduction}

Diesel railway vehicles play a significant role in non-electrified railway operation, heavy-haul railway freight transport, emergency rescue, and vehicle deployment [1-3]. By the end of 2015, 52\% of the world's railway vehicles used diesel as their power source [4]. The transmission system is one of the most critical systems in diesel railway vehicles, which influence safety and energy-saving performance [5]. Since the 1980s, the transmission system of diesel railway vehicles began to develop from the former direct current traction motor transmission system to an alternating current asynchronous traction motor transmission system. In recent years, researchers have begun to gradually apply a permanent magnet synchronous motor (PMSM) to the transmission systems of rail vehicles due to the advantages of high-power density. France's Alstom, the Japan Railway Corporation, Germany's Siemens, and the China Railway Rolling Stock Corporation (CRRC) all carried out technical research and commercial operations of PMSM. The results prove that PMSMs have a smaller size, lighter weight, and higher efficiency than asynchronous motors and synchronous excitation motors [6-9]. Therefore, PMSM has become a new trend for railway vehicle motors $[6,10]$. 
Among the large amount of research into PMSM, some has concentrated on optimizing the structure of the traction system. Takuma Ito et al. tried to use one inverter to control three or four PMSMs [11]. In Reference [12], Kassem Roumani et al. investigated the influence of geometric design variables on the machine's characteristics in a low voltage permanent magnet synchronous motor for in-wheel direct-drive application. Meanwhile, in order to make the PMSM traction system meet the railway vehicles' requirements, a significant amount of research into PMSM control strategy has been completed. Yifa et al. put forward a novel field weakening method to modify the current by the angle between the constant torque and the degressive voltage curve direction, which would make the motor operate steadily along the field-weakening curve [13]. Calleja et al. proposed an optimized modified direct-self-control (M-DSC) method, which can obtain better dynamic performance [14]. Zhao et al. designed a nonsingular terminal sliding mode observer (NTSMO) to detect the demagnetization of the permanent magnet and proposed an accurate torque control method to improve the torque control accuracy of PMSM [15]. Taniguchi et al. proposed a control method for the PMSM drive system without a position sensor, which can estimate the initial position and the speed of the rotor when the vehicle slides across the whole speed range. This method can also be used when the back electromotive force (back-EMF) voltage is higher than the inverter DC link voltage [16]. Zhao et al. designed a control scheme based on the most torque per ampere (MTPA) strategy to obtain high power density and achieve smooth transitions between the constant torque mode and the constant power (field weakening) mode. In addition, they designed a novel lowfrequency pulse width modulation (PWM) strategy for a smooth transition when changing the carrier frequency [17]. Some researchers have also studied the method for reducing the harmonic current of high-powered PMSM. In Reference [18], Zhang et al. analyzed the relationship between the load current of PMSM and the output voltage of the inverter using synchronous PWM, and they deduced the expression of current harmonics. A novel current harmonic distortion minimization PWM (CHMPWM) algorithm for the PMSM was constructed.

In References [11,13-18], it can be seen that PMSMs are now widely adopted as traction motors in railway vehicles. However, research on PMSMs as generators has largely been ignored, especially the system structure in which the generator and traction motor use PMSMs at the same time. In order to improve the efficiency of the whole transmission system to a greater extent, taking PMSM as both a generator and traction motor to construct a full permanent magnet transmission system (FPMTS) is a feasible and attractive scheme. In the transmission system, the control of the generator and traction motor, as well as the coordinated control, are always the core problems in system control. In this paper, the design scheme of the FPMTS is applied, problems encountered in the design are demonstrated, and the corresponding solutions are provided. The original induction motors' control methods and strategies are not fully adapted. Hence, a corresponding strategy needs to be studied. This paper makes a detailed analysis and introduction from the aspect of a coordinated control strategy of the diesel and the traction motor, the two degrees of freedom (2DOF) decoupling current regulator, the maximum torque control of a standardized unit current, the wheel slip protection control, and the fault protection strategy.

\section{Constitution and Features of FPMTS}

The main circuit of FPMTS is shown in Figure 1. The diesel drives the permanent magnet synchronous generator (PMSG) to generate a three-phase alternating current $(3 A C)$. Then, the alternating current $(A C)$ is converted to a direct current (DC) using the uncontrolled rectifier. After grounding detection, brake chopper, and auxiliary converter, DC is inverted $3 A C$ to provide electric power for PMSM via four inverters. The auxiliary converter gets its power from the DC link, which provides the power for vehicle auxiliary loads. The FPMTS is controlled by the traction control unit (TCU) and the motor control unit (MCU), which are placed in the traction converter box. TCU receives the driver's 
command and controls the diesel speed according to the motor state, which is fed back by the MCU. The MCU receives a torque command from TCU through the controller area network (CAN) bus and drives the PMSM. Using the pulse width modulation (PWM) method, the inverter converts the DC into variable voltage variable frequency (VVVF) AC, which, thus, realizes the vehicle's operation.

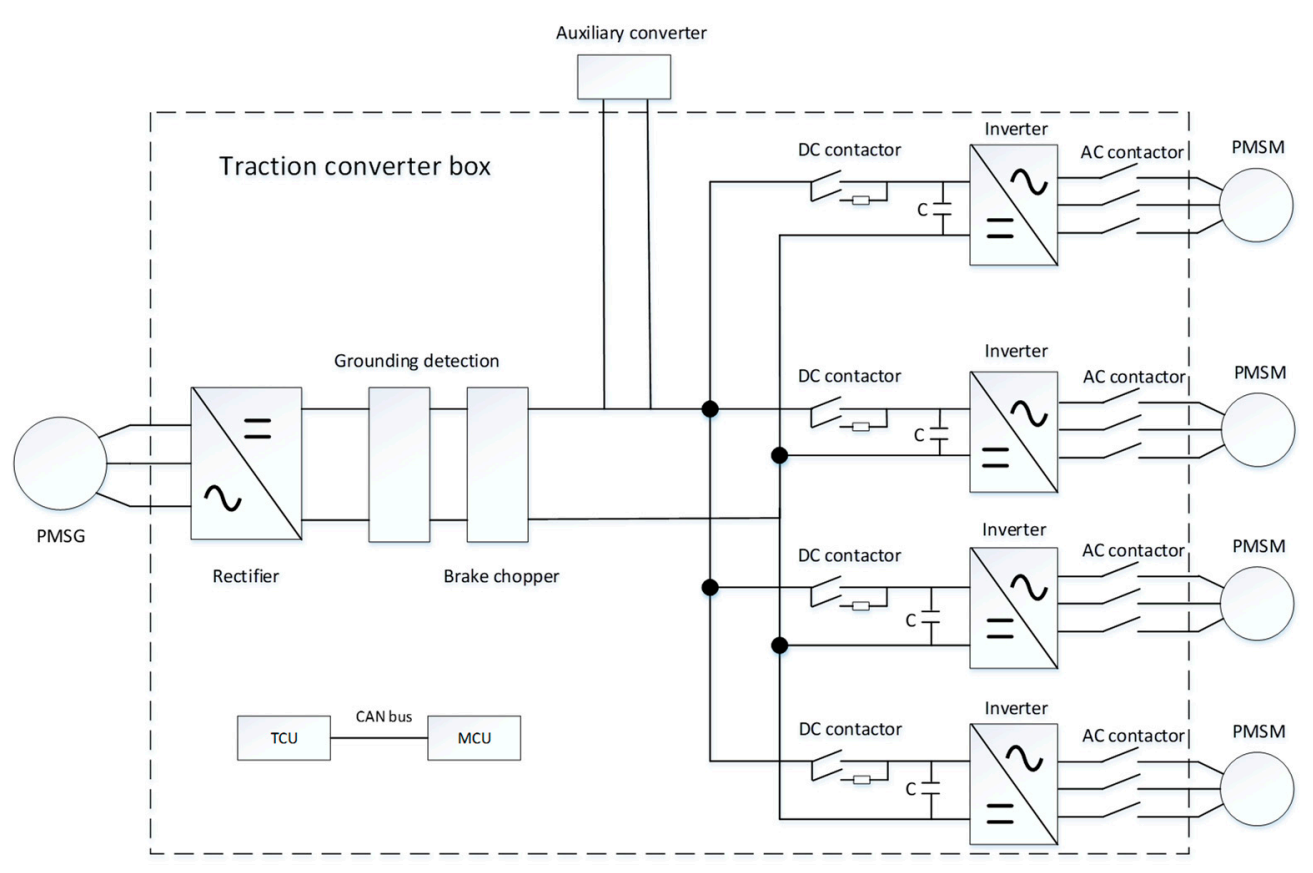

Figure 1. Main circuit of the full permanent magnet transmission system (FPMTS).

This project takes Cummins QSK19 diesel as the system power source. The diesel output power increases approximately linearly with a speed between $900 \mathrm{rpm}$ and $1300 \mathrm{rpm}$, changing only a little from $1300 \mathrm{rpm}$ to $1800 \mathrm{rpm}$. The PMSM operates at a constant torque control mode under $510 \mathrm{rpm}$ and at a constant power control mode from $510 \mathrm{rpm}$ to $2000 \mathrm{rpm}$. The conversion between the constant torque control mode and constant power control mode is automatically adjusted according to the DC link voltage. According to the characteristic of diesel and the requirement of the traction characteristic, the main parameters of FPMTS are decided (Table 1).

Table 1. Main parameters of the full permanent magnet transmission system (FPMTS).

\begin{tabular}{cccc}
\hline Parameter & Value & Parameter & Value \\
\hline Diesel idle speed $(\mathrm{r} / \mathrm{min})$ & 900 & PMSM rated speed $(\mathrm{r} / \mathrm{min})$ & 510 \\
Diesel rated speed $(\mathrm{r} / \mathrm{min})$ & 1800 & PMSM maximum speed $(\mathrm{r} / \mathrm{min})$ & 2000 \\
PMSG rated power $(\mathrm{kW})$ & 560 & PMSM Rated torque $(\mathrm{Nm})$ & 1800 \\
PMSG rated current $(\mathrm{A})$ & 630 & PMSM maximum torque $(\mathrm{Nm})$ & 3200 \\
PMSG rated voltage $(\mathrm{V})$ & 520 & Inverter maximum current $(\mathrm{A})$ & 700 \\
DC link rated Voltage $(\mathrm{V})$ & 750 & PMSM stator resistance $(\Omega)$ & 0.013 \\
PMSM rated power $(\mathrm{kW})$ & 100 & PMSM d-axis inductance $(\mathrm{mH})$ & 0.72 \\
PMSM rated current $(\mathrm{A})$ & 270 & PMSM q-axis inductance $(\mathrm{mH})$ & 1.54 \\
\hline
\end{tabular}

\section{Control and Protection Strategy}

\subsection{Coordinated Control of Diesel and Traction Motor}

Fuel consumption and mechanical wear increase when diesel runs at high speeds and light loads for a long time. Therefore, it is required to adjust the diesel speed dynamically with the load changes. The FPMTS is also an active loading system. Improper loading processes will stop the diesel, especially in the process of diesel acceleration or deceleration. 
Solving the coordinated control of the diesel and the traction motor is the main problem of FPMTS.

In cruise mode, the system only needs to ensure that the diesel's output power (i.e., the power for traction motors, excluding other auxiliary power) is greater than the traction power required for traction motors, and that the diesel is controlled in minimum fuel consumption mode. Nevertheless, during vehicle acceleration or deceleration, the traction power changes rapidly with vehicle speed, which will, thus, exceed the diesel maximum output power, resulting in the diesel stopping. Moreover, the energy supply system, composed of the diesel and the PMSG, is a large inertial system with a limited capacitor serving as the energy storage in the DC link. Therefore, the DC link voltage changes rapidly, and it is difficult to regulate it in real-time. Therefore, the control program must detect the change process of the diesel and the motor, and limit the torque of the motor automatically when necessary.

Considering the output characteristics of the diesel and motor, we propose the following method. When the motor speed is fewer than $100 \mathrm{rpm}$, the diesel speed increase from $900 \mathrm{rpm}$ to $1300 \mathrm{rpm}$. When the motor speed enhances from $100 \mathrm{rpm}$ to $510 \mathrm{rpm}$, the diesel speed increase proportionally from $1300 \mathrm{rpm}$ to $1800 \mathrm{rpm}$. The speed relation curve of the diesel and the motor is shown in Figure 2. Figure 3 shows the control flow chart of the coordinated control strategy.

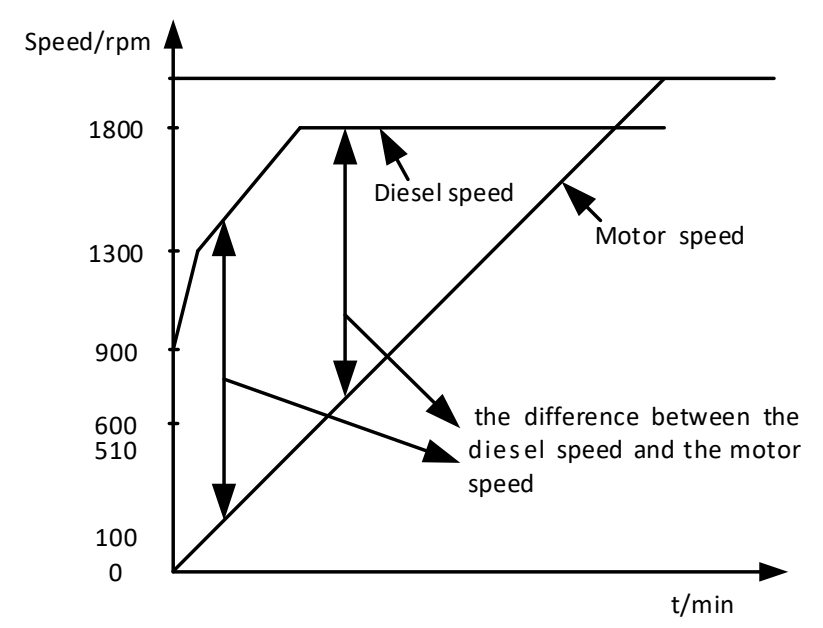

Figure 2. Speed relation for the diesel and the motor.

\subsection{Design of the 2DOF Decoupling Current Regulator}

In order to reduce fuel consumption, when the vehicle is in cruise mode, diesel speed and vehicle speed (motor speed) are required to be decoupled. In extreme cases, when the diesel runs at $900 \mathrm{rpm}$, the DC link voltage is $320 \mathrm{~V} \mathrm{DC}$. When the PMSM runs at the maximum speed (2000 rpm), the traction motor needs a weak magnetic expansion speed, which is up to four times. The current loop needs a strong adaptability to voltage and has a wide bandwidth. For this reason, the 2DOF decoupling current regulator is adopted based on decoupling control of dq-axes. Then, all poles and zeros of the current loop are configured by introducing virtual resistance to achieve fast responses to current command, adjusting quickly to deal with back-EMF disturbance.

In the dq reference frame of rotor permanent magnet orientation, the voltage equation of PMSM is as follows:

$$
\begin{gathered}
L_{\mathrm{d}} \frac{\mathrm{d} i_{\mathrm{d}}}{\mathrm{d} t}=u_{\mathrm{d}}-R_{\mathrm{s}} i_{\mathrm{d}}+\omega_{\mathrm{e}} L_{\mathrm{q}} i_{\mathrm{q}} \\
L_{\mathrm{q}} \frac{\mathrm{d} i_{\mathrm{q}}}{\mathrm{d} t}=u_{\mathrm{q}}-R_{\mathrm{s}} i_{\mathrm{q}}-\omega_{\mathrm{e}} L_{\mathrm{d}} i_{\mathrm{d}}-\omega_{\mathrm{e}} \psi_{\mathrm{f}}
\end{gathered}
$$

where $L_{\mathrm{d}}$ and $L_{\mathrm{q}}$ are the dq-axes stator inductances, $R_{\mathrm{s}}$ is the stator resistance, $u_{\mathrm{d}}$ and $u_{\mathrm{q}}$ are the dq-axes stator voltages, $i_{\mathrm{d}}$ and $i_{\mathrm{q}}$ are the dq-axes stator currents, $\omega_{\mathrm{e}}$ is the rotor electrical angular velocity, and $\psi_{\mathrm{f}}$ is the rotor permanent magnetic flux linkage. 


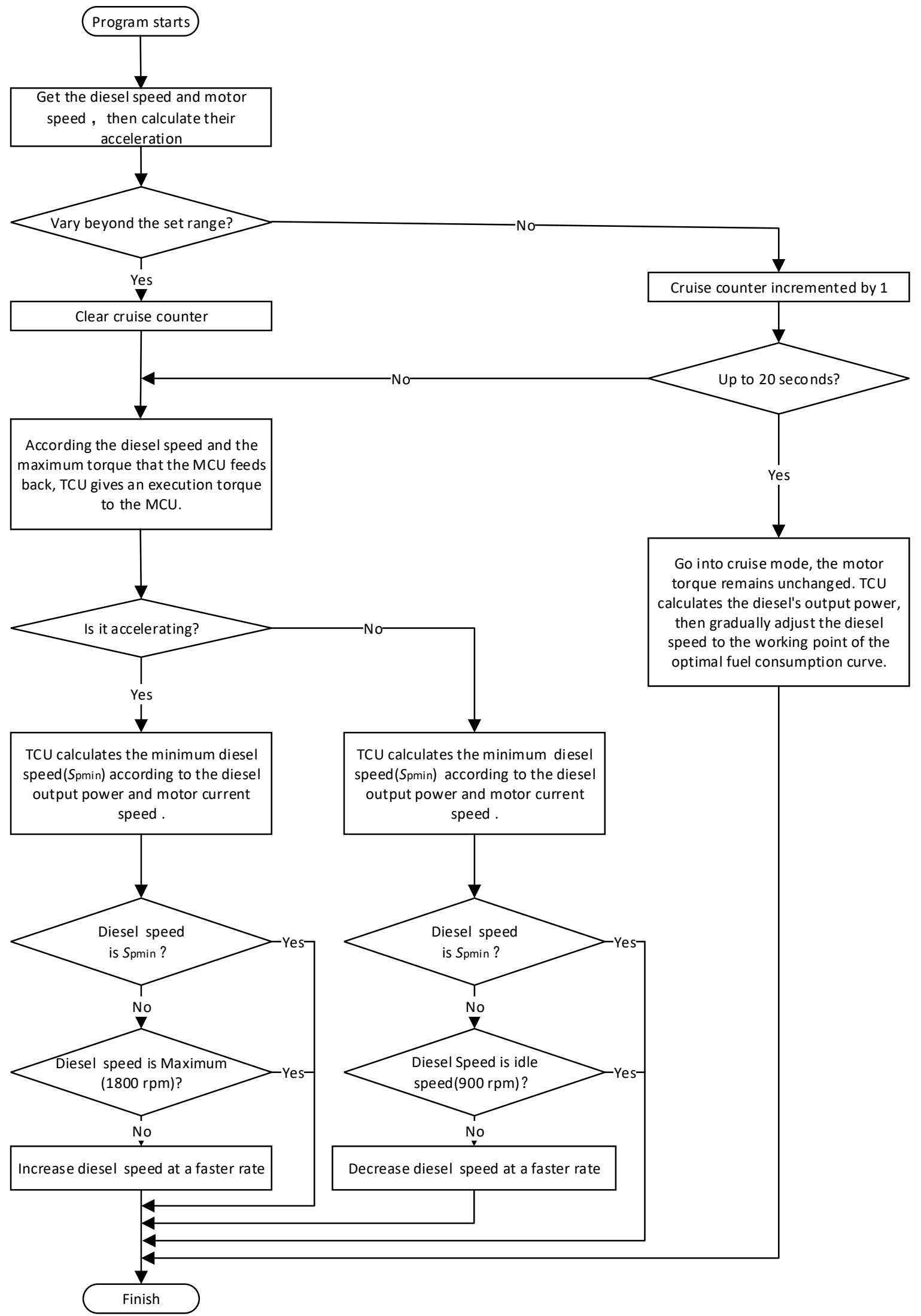

Figure 3. Control flow chart of the coordinated control strategy. 
The 2DOF current regulator is designed by introducing virtual resistance and crossfeedback decoupling control. $u_{\mathrm{d}}$ and $u_{\mathrm{q}}$ can be obtained from the following equation.

$$
\begin{aligned}
& u_{\mathrm{d}}=u_{\mathrm{d}}^{\prime}-R_{\mathrm{ad}} i_{\mathrm{d}}-\omega_{\mathrm{e}} L_{\mathrm{q}} i_{\mathrm{q}} \\
& u_{\mathrm{q}}=u_{\mathrm{q}}^{\prime}-R_{\mathrm{aq}} i_{\mathrm{q}}+\omega_{\mathrm{e}} L_{\mathrm{d}} i_{\mathrm{d}}+\omega_{\mathrm{e}} \psi_{\mathrm{f}}
\end{aligned}
$$

where $R_{\mathrm{ad}}$ and $R_{\mathrm{aq}}$ are the virtual resistances. $u_{\mathrm{d}}^{\prime}$ and $u_{\mathrm{q}}^{\prime}$ are the outputs of the dq-axes current proportional integral (PI) regulator.

$$
\begin{aligned}
& u_{\mathrm{d}}^{\prime}=\left(k_{\mathrm{pd}}+\frac{k_{\mathrm{id}}}{s}\right)\left(i_{\mathrm{d}, \text { ref }}-i_{\mathrm{d}}\right) \\
& u_{\mathrm{q}}^{\prime}=\left(k_{\mathrm{pq}}+\frac{k_{\mathrm{iq}}}{s}\right)\left(i_{\mathrm{q}, \text { ref }}-i_{\mathrm{q}}\right)
\end{aligned}
$$

Substituting Equation (2) into Equation (1) obtains the following.

$$
\begin{aligned}
& L_{\mathrm{d}} \frac{\mathrm{d} i_{\mathrm{d}}}{\mathrm{d} t}=u_{\mathrm{d}}^{\prime}-\left(R_{\mathrm{s}}+R_{\mathrm{ad}}\right) i_{\mathrm{d}} \\
& L_{\mathrm{q}} \frac{\mathrm{d} i_{\mathrm{q}}}{\mathrm{d} t}=u_{\mathrm{q}}^{\prime}-\left(R_{\mathrm{s}}+R_{\mathrm{aq}}\right) i_{\mathrm{q}}
\end{aligned}
$$

Thus, the decoupling of dq-axes current loop is realized. Let the design bandwidth of the current loop be $\omega_{\mathrm{b}}$, taking the virtual resistance value as $R_{\mathrm{ad}}=\omega_{\mathrm{b}} L_{\mathrm{d}}-R_{\mathrm{s}}$, $R_{\mathrm{aq}}=\omega_{\mathrm{b}} L_{\mathrm{q}}-R_{\mathrm{s}}$, the parameter of PI regulator as $k_{\mathrm{pd}}=\omega_{\mathrm{b}} L_{\mathrm{d}}, k_{\mathrm{id}}=\omega_{\mathrm{b}}\left(R_{\mathrm{s}}+R_{\mathrm{ad}}\right)$, $k_{\mathrm{pq}}=\omega_{\mathrm{b}} L_{\mathrm{q}}$, and $k_{\mathrm{iq}}=\omega_{\mathrm{b}}\left(R_{\mathrm{s}}+R_{\mathrm{aq}}\right)$. The obtained closed-loop transfer function of the PMSM current loop is shown below.

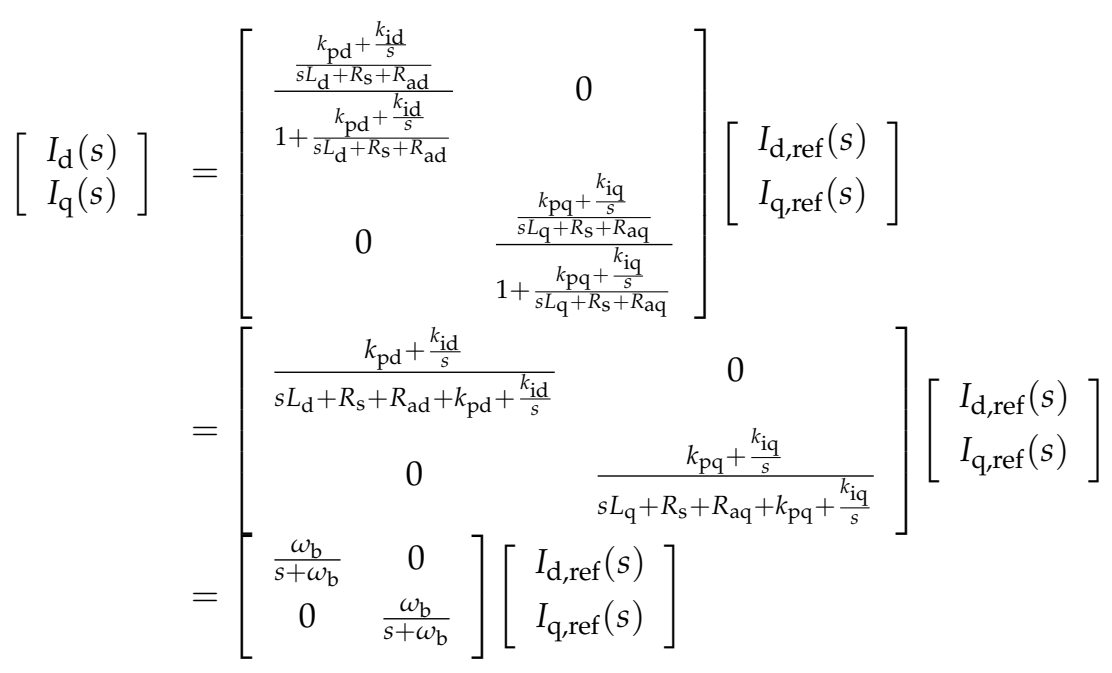

In the above process, the d-axis and q-axis channels each have one pair of zeroes and poles equal to $-\omega_{\mathrm{b}}$, which are canceled out. Moreover, each channel has one pole equal to $-\omega_{\mathrm{b}}$. They all have fast convergence speed and good stability. For comparison, the traditional PI regulator parameter design method does not introduce virtual resistance $\left(R_{\mathrm{ad}}=R_{\mathrm{aq}}=0\right)$, and the canceled poles are the slow poles equal to $-R_{\mathrm{s}} / L_{\mathrm{d}}$ and $-R_{\mathrm{s}} / L_{\mathrm{q}}$, which are much closer to the origin than $-\omega_{\mathrm{b}}$. Using root locus analysis, it is easy to discern that, unless the dq-axes are decoupled accurately with the increase in the motor speed, there are two closed root trajectories that begin at the slow poles of the open loop. After two slow poles meet on the negative real axis, they change along the positive and negative direction of the virtual axis. The damping becomes smaller and smaller, and leads to a continuous low frequency current oscillation response. Although increasing the bandwidth of the current loop can significantly reduce this oscillation, the bandwidth of the current loop is limited by the inverter modulation frequency. In this project, the power device is an insulated gate bipolar transistor (IGBT) of $1700 \mathrm{~V}$ and $1400 \mathrm{~A}$. In order to limit the IGBT loss, the modulation frequency is $2000 \mathrm{~Hz}$. 
On the basis of the 2DOF decoupling design of the current regulator, the integral anti-saturation measures are added to the block diagram of the current regulator (Figure 4), where $\left|u_{\mathrm{dq}}\right|_{\max }$ is the maximum amplitude of the motor stator voltage vector, and $\bar{u}_{\mathrm{d}}$ and $\bar{u}_{\mathrm{q}}$ are the actual voltages applied to the motor stator. The algorithm ensures that the actual applied voltage vector $\bar{u}_{\mathrm{dq}}$ is limited within the voltage circle specified in $\left|u_{\mathrm{dq}}\right|_{\max }$ and has the same direction as $u_{\mathrm{dq}}$. When the voltage vector changes from the outside of the voltage circle to the inside, this design helps the current loop recover smoothly and fast.

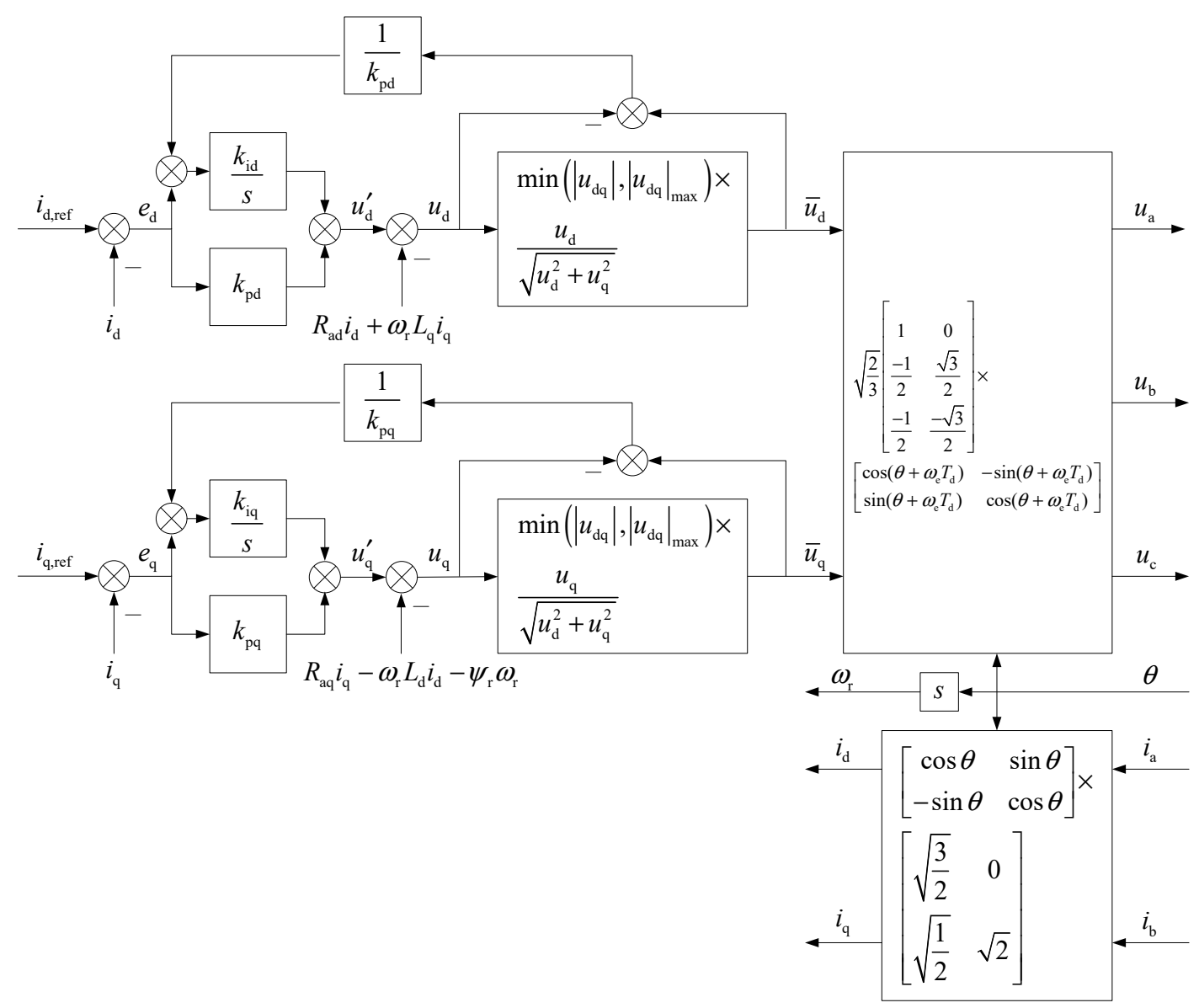

Figure 4. Design scheme of the current regulator.

In the practice, considering the delay of 1.5 modulation cycles from filling duty cycle register to PWM output, the motor stator voltage in the static coordinate system is

$$
\left[\begin{array}{l}
u_{\mathrm{a}} \\
u_{\mathrm{b}} \\
u_{\mathrm{c}}
\end{array}\right]=\sqrt{\frac{2}{3}}\left[\begin{array}{cc}
1 & 0 \\
\frac{-1}{2} & \frac{\sqrt{3}}{2} \\
\frac{-1}{2} & \frac{-\sqrt{3}}{2}
\end{array}\right] \times\left[\begin{array}{cc}
\cos \left(\theta+\omega_{\mathrm{e}} T_{\mathrm{d}}\right) & -\sin \left(\theta+\omega_{\mathrm{e}} T_{\mathrm{d}}\right) \\
\sin \left(\theta+\omega_{\mathrm{e}} T_{\mathrm{d}}\right) & \cos \left(\theta+\omega_{\mathrm{e}} T_{\mathrm{d}}\right)
\end{array}\right]\left[\begin{array}{c}
\bar{u}_{\mathrm{d}} \\
\bar{u}_{\mathrm{q}}
\end{array}\right]
$$

where $T_{\mathrm{d}}=1.5 T_{\mathrm{s}}, T_{\mathrm{s}}$ is the PWM modulation cycle, i.e., the regulator output voltage vector has an advanced $\omega_{\mathrm{e}} T_{\mathrm{d}}$ electrical angle.

\subsection{Maximum Torque Control of a Standardized Unit Current}

In order to improve the efficiency of the transmission system, maximum torque per ampere (MTPA) is adopted before the PMSM entering the field weakening control mode. 
In this project, maximum torque control of the standardized unit current was used. For interior PMSM, electromagnetic torque is expressed by Equation (7).

$$
T_{\mathrm{m}}=p_{\mathrm{n}}\left[\psi_{\mathrm{f}} i_{\mathrm{q}}+\left(L_{\mathrm{d}}-L_{\mathrm{q}}\right) i_{\mathrm{q}} i_{\mathrm{d}}\right]
$$

where $T_{\mathrm{m}}$ is the electromagnetic torque, $i_{\mathrm{d}}$ and $i_{\mathrm{q}}$ are dq-axes currents separately, $P_{\mathrm{n}}$ is the number of pole pairs, and $\psi_{\mathrm{f}}$ is the permanent magnet flux linkage.

In order to obtain the maximum torque per unit current, $i_{\mathrm{d}}$ and $i_{\mathrm{q}}$ should be satisfied.

$$
\begin{aligned}
& \frac{\partial\left(T_{\mathrm{m}} / i_{\mathrm{s}}\right)}{\partial i_{\mathrm{d}}}=0 \\
& \frac{\partial\left(T_{\mathrm{m}} / i_{\mathrm{s}}\right)}{\partial i_{\mathrm{q}}}=0
\end{aligned}
$$

Put Equation (7) and the motor stator current $\left(i_{\mathrm{s}}=\sqrt{i_{\mathrm{d}}^{2}+i_{\mathrm{q}}^{2}}\right)$ in Equation (8), then $i_{\mathrm{d}}$ can be expressed by Equation (9).

$$
i_{\mathrm{d}}=\frac{\psi_{\mathrm{f}}}{2\left(L_{\mathrm{q}}-L_{\mathrm{d}}\right)} \pm \sqrt{\frac{1}{4}\left(\frac{\psi_{\mathrm{f}}}{L_{\mathrm{q}}-L_{\mathrm{d}}}\right)^{2}+i_{\mathrm{q}}^{2}}
$$

For the salient pole PMSM, $L_{\mathrm{q}}>L_{\mathrm{d}}, i_{\mathrm{d}}<0$, the sign before the root in Equation (9) should be negative. Finally, the relation between $i_{\mathrm{d}}$ and $i_{\mathrm{q}}$ is expressed in Equation (10).

$$
i_{\mathrm{d}}=\frac{\psi_{\mathrm{f}}}{2\left(L_{\mathrm{q}}-L_{\mathrm{d}}\right)}-\sqrt{\frac{1}{4}\left(\frac{\psi_{\mathrm{f}}}{L_{\mathrm{q}}-L_{\mathrm{d}}}\right)^{2}+i_{\mathrm{q}}^{2}}
$$

According to a given torque command, Equations (7) and (10) obtains the value of $i_{\mathrm{d}}$ and $i_{\mathrm{q}}$ via an iterative calculation. To avoid the iterative operation, the per unit value of current and torque can be expressed as $i_{\mathrm{dn}}=i_{\mathrm{d}} / i_{\mathrm{b}}, i_{\mathrm{qn}}=i_{\mathrm{q}} / i_{\mathrm{b}}$, and $T_{\mathrm{n}}=T_{\mathrm{m}} / T_{\mathrm{b}}$ [19]. The value of $i_{\mathrm{b}}$ and $T_{\mathrm{b}}$ is as follows.

$$
\begin{aligned}
i_{\mathrm{b}} & =\frac{\psi_{\mathrm{f}}}{L_{\mathrm{q}}-L_{\mathrm{d}}} \\
T_{\mathrm{b}} & =p_{\mathrm{n}} \psi_{\mathrm{f}} i_{b}
\end{aligned}
$$

Then, the per unit value of torque $T_{\mathrm{n}}$ can be expressed by the equation below.

$$
\begin{aligned}
& T_{\mathrm{n}}=\sqrt{i_{\mathrm{dn}}\left(i_{\mathrm{dn}}-1\right)^{3}} \\
& T_{\mathrm{n}}=\frac{T_{\mathrm{m}}}{T_{\mathrm{b}}}=\frac{i_{\mathrm{q}}}{i_{\mathrm{b}}}\left[1-\frac{\left(L_{\mathrm{q}}-L_{\mathrm{d}}\right)}{\psi_{\mathrm{f}}} i_{\mathrm{d}}\right]=i_{\mathrm{qn}}\left[1-i_{\mathrm{dn}}\right]=\frac{i_{\mathrm{qn}}}{2}\left(1+\sqrt{1+4 i_{\mathrm{qn}}^{2}}\right)
\end{aligned}
$$

By making and querying tables of $T_{\mathrm{n}}-i_{\mathrm{dn}}$ and $T_{\mathrm{n}}-i_{\mathrm{qn}}$, the per unit values of $i_{\mathrm{qn}}$ and $i_{\mathrm{dn}}$ can be obtained. Finally, the reference values $i_{\mathrm{d}}$ and $i_{\mathrm{q}}$ can be obtained when combined with parameters of the PMSM.

In fact, as the motor current increases, the q-axis inductance changes due to the influence of the armature reaction [20-22]. The change of the permanent magnetic flux and $\mathrm{d}$-axis inductance is small. Therefore, the online adjust of q-axis inductance based on its changes is necessary.

\subsection{Wheel Slip Protection Control Strategy}

Wheel slip protection is an essential function for railway vehicles, and prevents damage to the wheels and rails caused by wheel slips. Due to the MCU's quick response ability, the focus of the wheel slip protection is to detects the slip state quickly and accurately. In this project, the slip state is judged by calculating the deviation of velocity and acceleration for motors.

The MCU compares the real-time speed of each motor with the minimum value of the four motors. If the speed deviation exceeds the threshold, the MCU reduces the execution torque in proportion. The MCU compares the real-time acceleration of the motor with the 
given threshold. If the acceleration difference exceeds the threshold, the MCU reduces the execution torque in proportion as well. The greater the speed deviation, the greater the decrease in the motor torque ratio. In extreme cases, the MCU rapidly reduces the motor torque to zero to prevent wheel slip. The MCU detects motor speed and calculates angular acceleration every $10 \mathrm{~ms}$. When the MCU exits the wheel slip protection, the execution torque remains unchanged for a certain period of time $(200 \mathrm{~ms})$, and then increases to the aimed value given by TCU.

Taking the number 1 motor as an example, the block diagram of wheel slip protection is shown in Figure 5.

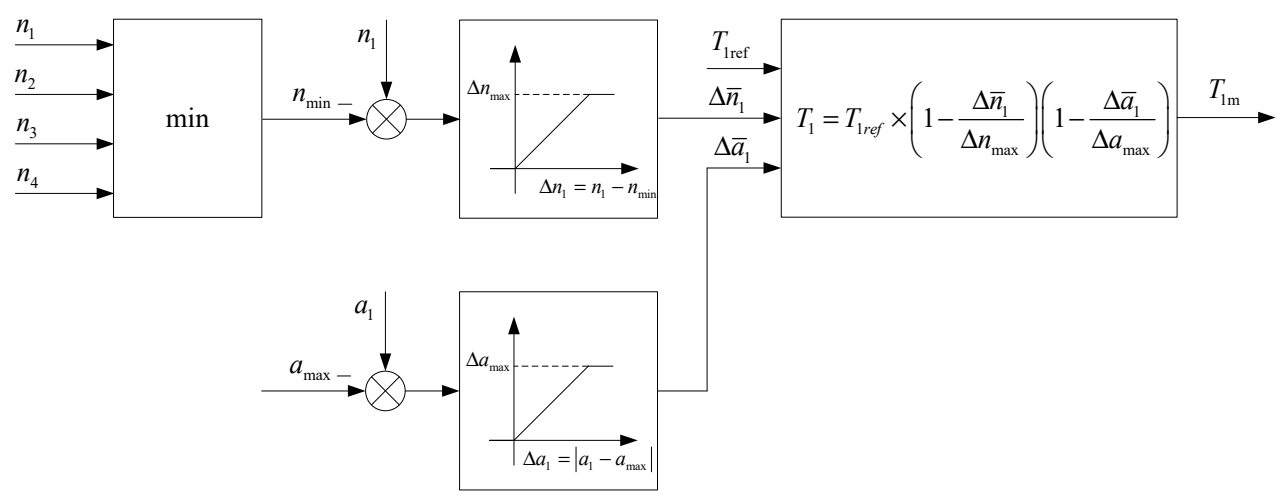

Figure 5. The block diagram of wheel slip protection.

In Figure $5, n_{1}, n_{2}, n_{3}$, and $n_{4}$ are the real-time speeds of the four motors. $n_{\min }$ is the minimum speed of $n_{1}, n_{2}, n_{3}$, and $n_{4} . \Delta n_{1}$ is the difference between $n_{1}$ and $n_{\min } \cdot a_{1}$ is the acceleration of the number 1 motor. $a_{\max }$ is the reference value of maximum acceleration. $\Delta a_{1}$ is the absolute value of the difference between $a_{1}$ and $a_{\max } . \Delta \bar{a}_{1}$ is the value of $\Delta a_{1}$ after the clipping algorithm. $T_{1 \text { ref }}$ is the motor torque given by the TCU, and $T_{1 \mathrm{~m}}$ is the execution torque of the number 1 motor.

$\Delta n_{\max }$ and $\Delta a_{\max }$ are programmable parameters, which can be modified. If the value of $\Delta n_{\max }$ and $\Delta a_{\max }$ become smaller, the slip protection control effect becomes stronger. The flow chart of the algorithm is shown in Figure 6, where $n_{\text {anti }}$ is the preset value of the slip protection counter.

\subsection{Fault Detection and Restart Control}

The MCU is responsible for fault detection and system protection functions. The faults detected by the hardware detection circuit include the IGBT drive fault, IGBT fault, overcurrent, main circuit overvoltage, and control board under voltage. The faults detected by the software include system self-check fault, contactor fault, inverter overheating, motor overheating, over speed fault, and sensor faults. The faults are classified, according its type and severity level. When the fault occurs, the fault information is submitted to the TCU via the CAN bus.

When the faults occur, they are detected by the hardware and the MCU immediately blocks the IGBT drive signal before de-energizing the DC contactor. If the inverter output current does not decrease to zero within the specified time, the AC contact is de-energized. When the faults occur, they are detected by the software and the MCU checks the sensor first. If the fault is not the sensor's fault, the MCU provides a different treatment according to different situations. 


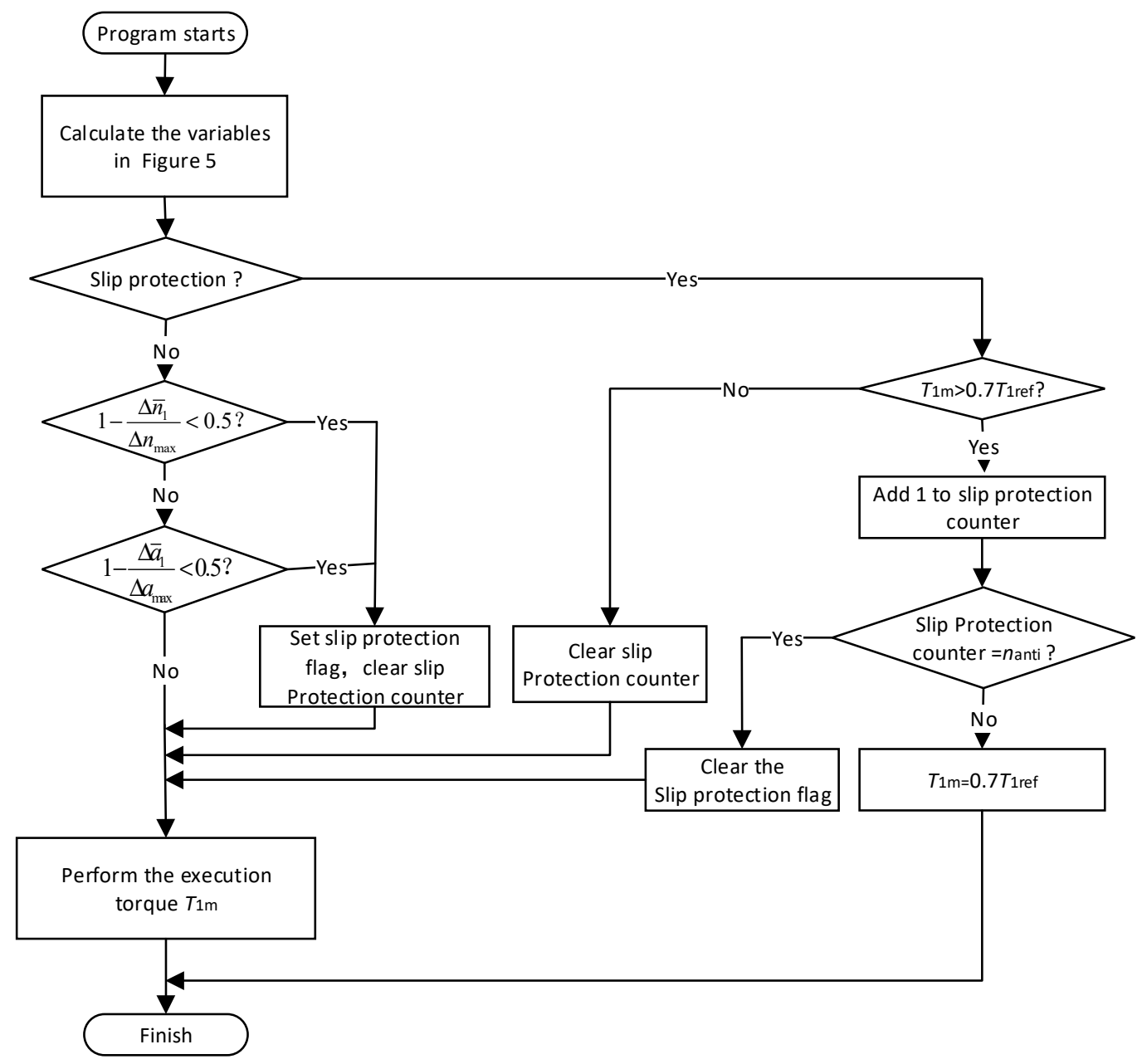

Figure 6. Control flow chart of wheel slip protection.

The following is a brief description of the restart control strategy after the fault is cleared. After receiving the restart command, the MCU resets the PI regulator and unlocks the PWM. Before the DC contactor is energized, if the main circuit voltage is lower than the threshold, the motor operates in an electric braking mode, and the main circuit voltage is pumped to the supply voltage. The electric braking torque is very little, which does not affect the running of the vehicle. When the demagnetization current is established, the voltage loop controls the main circuit voltage to be close to the DC supply voltage. After the DC contactor is energized, the program responds to the torque command and enters the driving state. Then, the voltage loop exits and the restart progress is finished. The flow chart of the restart control is shown in Figure 7.

In the above restart control process, if a serious fault occurs, the DC contactor should be de-energized as soon as possible. Only when the PWM signal is blocked and the stator current of the motor does not decrease to the preset value within the specified time, the $\mathrm{AC}$ contactor is de-energized. Once the AC contactor is de-energized, the program is considered unsuitable for the restart operation. 


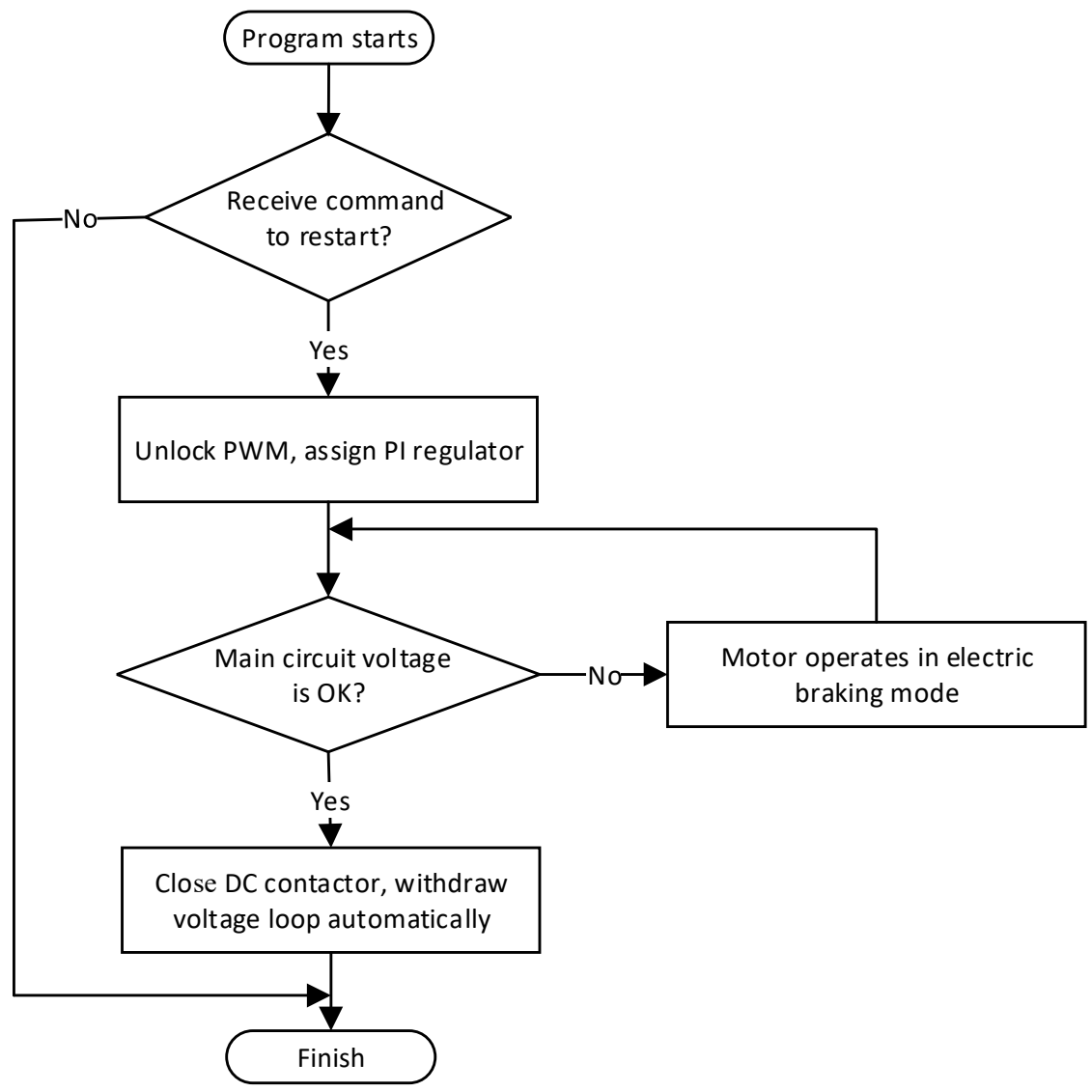

Figure 7. Flow chart of the restart control.

\section{Simulation}

We built a simulation model for the motor control system in MATLAB/Simulink. In order to verify the system performance after using the 2DOF regulator algorithm, the 2DOF regulator and traditional PI regulator were applied to the system, respectively, and the results of the two regulators were compared. The motor parameters are listed in Table 1. The sampling frequency was $0.0005 \mathrm{~s}$ and the bandwidth of the current loop was $160 \mathrm{~Hz}$ $\left(\omega_{\mathrm{b}}=1000 \mathrm{rad} / \mathrm{s}\right)$. Figure 8a shows the current and torque responses controlled by the traditional PI regulator when the motor accelerated and decelerated from 0 to $1000 \mathrm{rpm}$ with an $800 \mathrm{Nm}$ load. From Figure 8a, it is apparent that good performance was obtained. Figure $8 \mathrm{~b}$ shows current and torque responses controlled by the traditional PI regulator when the motor accelerated and decelerated from 0 to $2000 \mathrm{rpm}$ with an $800 \mathrm{Nm}$ load. As shown in Figure 8b, there was marked oscillation when the motor operated at high speeds.

In order to solve the problem of current oscillation during the motor's high-speed operation, we adopted a 2DOF decouple current regulator. Figure 9a shows the current and torque responses when the motor accelerated or decelerated from 0 to $2000 \mathrm{rpm}$ with $800 \mathrm{Nm}$ loads. The 2DOF method was adopted without the decoupling control of the $\mathrm{dq}$-axes. Figure $9 \mathrm{~b}$ shows the current and torque responses in the same operation condition but with the 2DOF method decoupling control of the dq-axes. By comparing Figure 9a with Figure 8b, it is clear that the current with the 2DOF method performed better than the traditional PI method, as there was no oscillation at high speeds. By comparing Figure 9a with Figure 9b, it can be seen that the current and torque in the 2DOF method did not have much of a difference with or without the decoupling of the dq-axes. Therefore, the superiority of the 2DOF method is clear, as it improves performance. Figure 9c shows the current and torque responses for the 2DOF decoupling current regulator when the motor operated in the deep flux. It weakened conditions in the constant power mode $(500 \mathrm{Nm}$ 
output and $2000 \mathrm{rpm}$ ). As shown in Figure 9c, the deep flux weakening control made the motor current close to its maximum value.

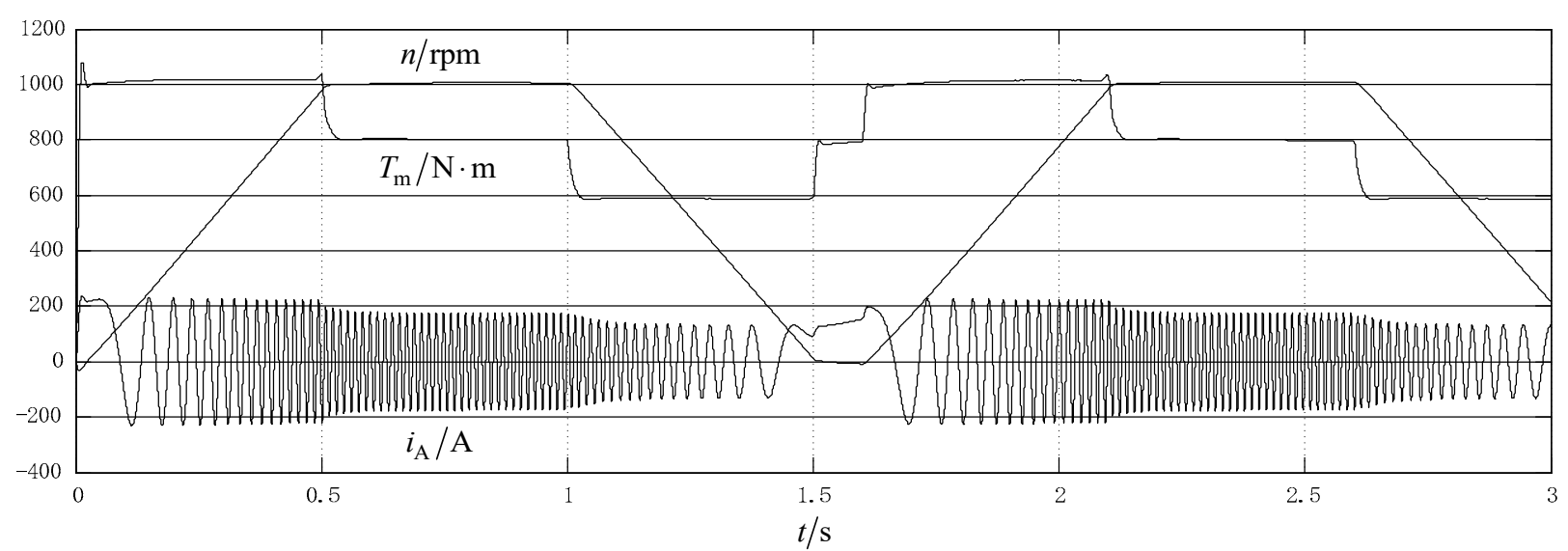

(a)

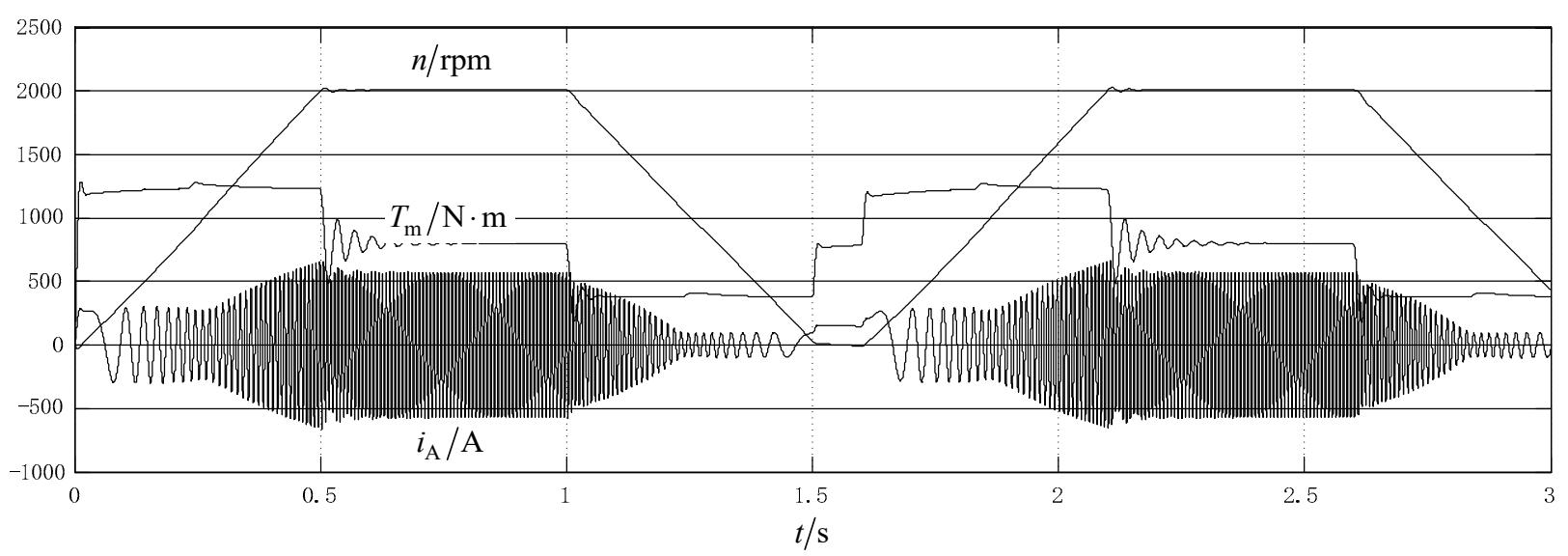

(b)

Figure 8. Current and torque responses adopted a traditional proportional integral (PI) regulator: (a) the motor operates at low-speed and (b) the motor operates at high-speed.

Figure 10 shows a restart process when a fault was detected. The serious fault occurred at $0.05 \mathrm{~s}$, then the PWM was blocked, and the DC contactor was de-energized. The energy stored in the three-phase inductance of the traction motor made the DC link voltage rise for a short amount of time, and then fall back gradually. The system restarted at $0.07 \mathrm{~s}$, and then the electric brake torque was generated to maintain the DC link voltage and establish the demagnetization current for the traction motor. The restart process finished at $0.15 \mathrm{~s}$ and the torque command responded. As can be seen from Figure 10, the system designed in this project quickly responded to failures and had a good restart performance. 


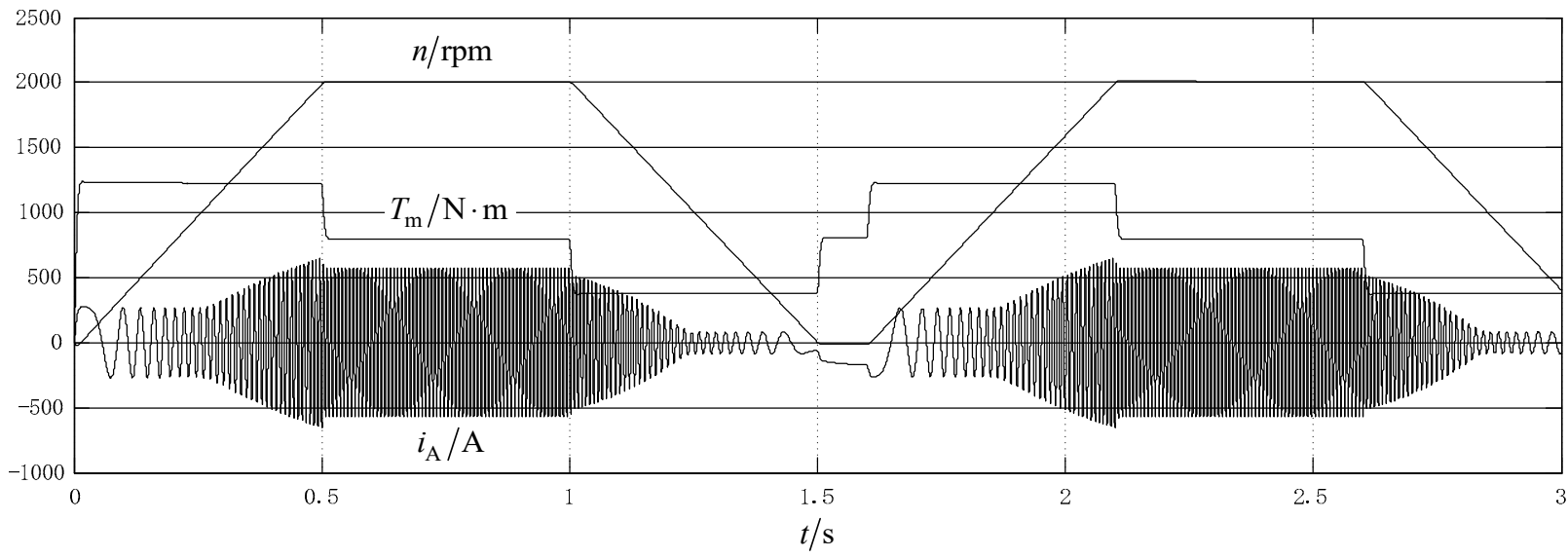

(a)

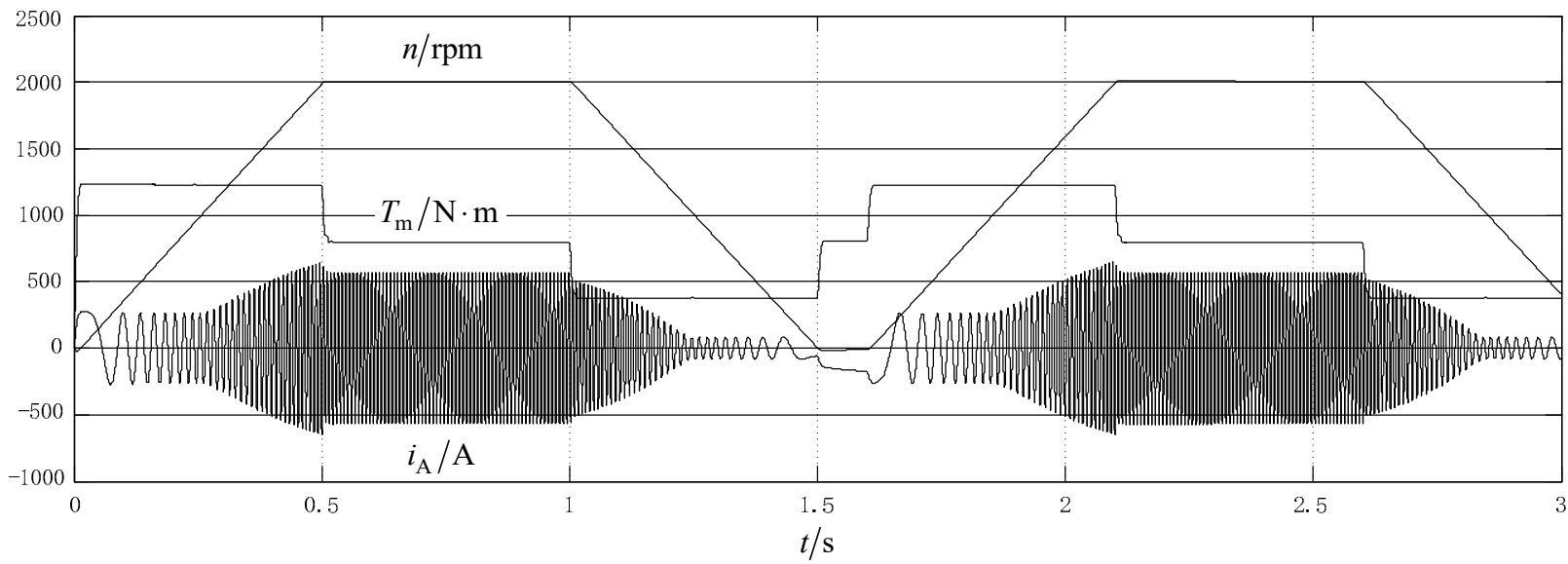

(b)

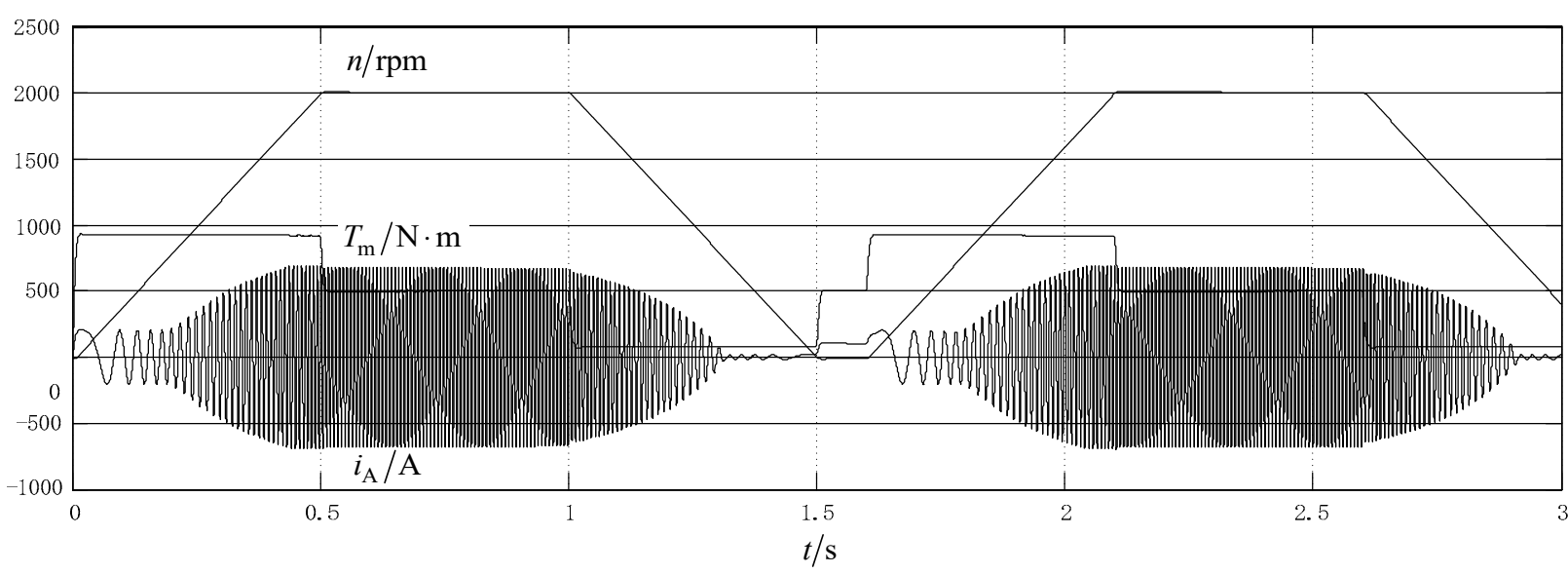

(c)

Figure 9. Current and torque responses adopted two degrees of freedom (2DOF) regulator: (a) the motor operates at high-speed without decoupling the dq-axis, (b) the motor operates at high-speed with a decoupling dq-axis, and (c) the motor operates in a deep flux weakening condition. 


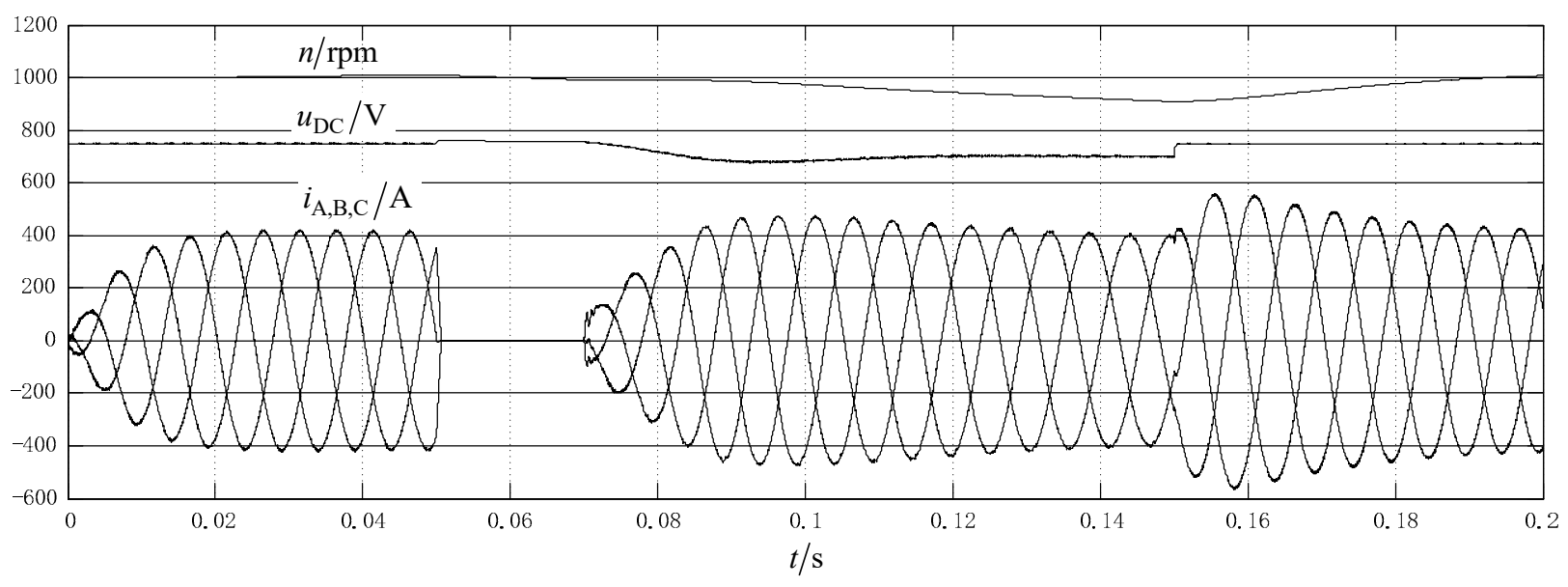

Figure 10. Responses in the restart process.

\section{Experiment}

In order to verify the correctness of the theoretical analysis and system performance, the system experiments were carried out on the FPMTS test platform (Figure 11). Figure 12a shows current responses controlled by a traditional PI regulator when the motor accelerated from $1000 \mathrm{rpm}$ to $2000 \mathrm{rpm}$ with an $800 \mathrm{Nm}$ load. As shown in Figure 12a, there were marked oscillations in the current responses. Figure $12 \mathrm{~b}$ shows motor current response waveforms in the 2DOF regulator when the motor operated in the same condition. As shown in Figure 12b, there was no oscillation and the current response significantly improved.

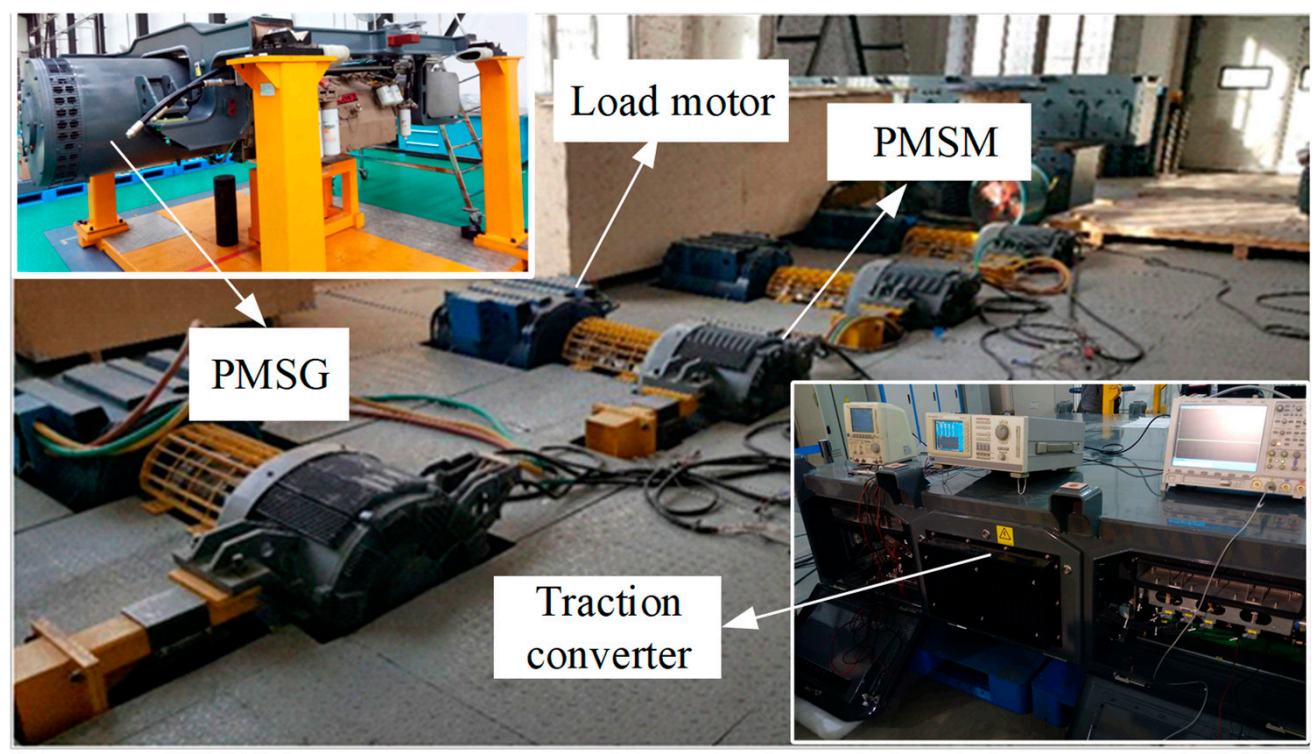

Figure 11. The FPMTS test platform.

Figure 13 shows the experimental results of the restart process on the FPMTS test platform. The serious fault occurred at $0.1 \mathrm{~s}$. Then the MCU block PWM and the DC contactor was de-energized. As the auxiliary loads on the vehicle continued to consume electric energy, the DC link voltage dropped. The system restarted at $0.4 \mathrm{~s}$, and then the electric brake torque was generated, which was controlled by the voltage loop to maintain the DC link voltage at $600 \mathrm{~V}$ and establish the demagnetization current for the traction motor. The DC contactor was energized at $1.4 \mathrm{~s}$, so the voltage rose to $750 \mathrm{~V}$, and the voltage loop automatically exited. Then, the program responded to the torque command and entered the driving state. The experimental results showed that the system designed in 
this project could quickly respond to failures and had a good restart performance without the system stopping.
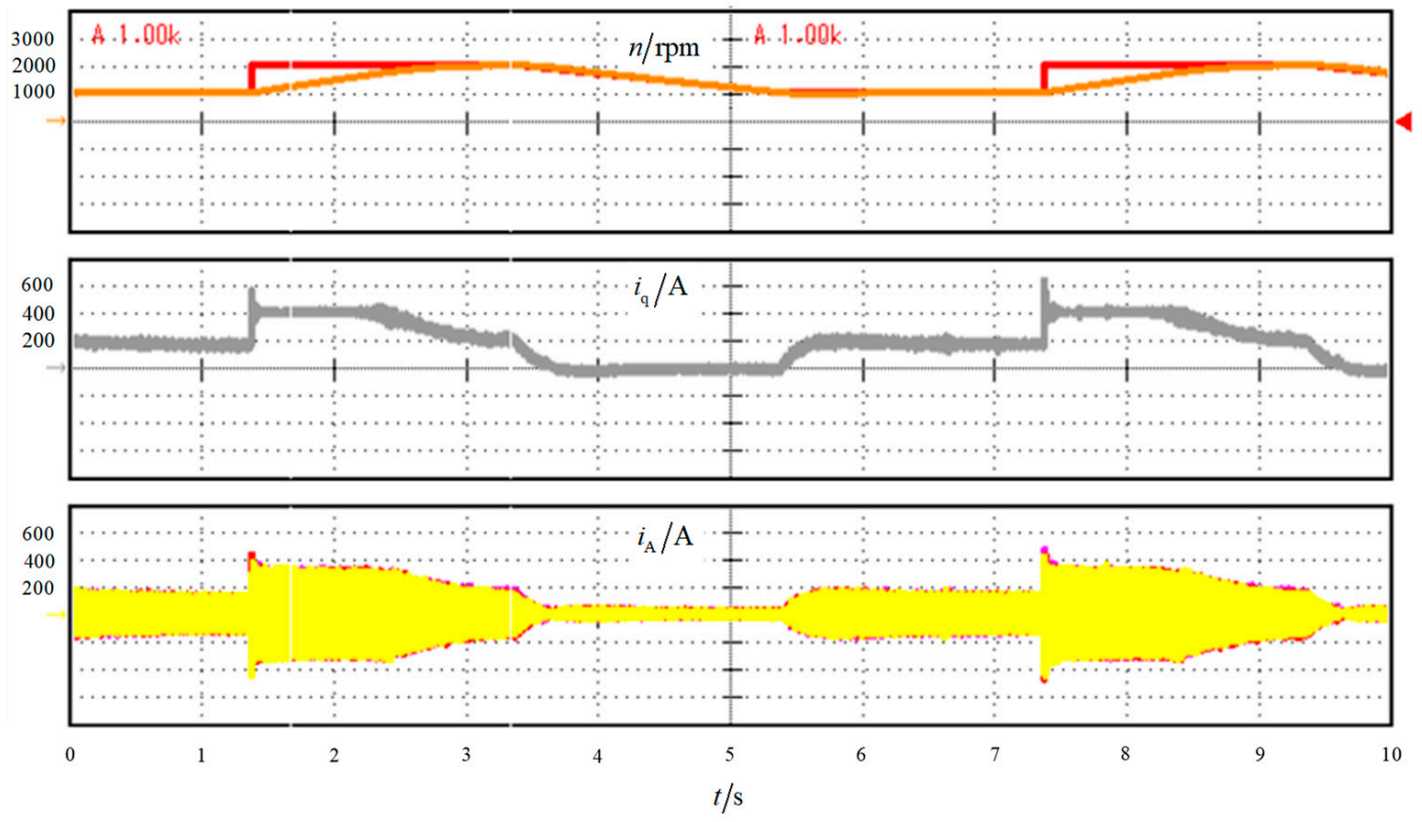

(a)
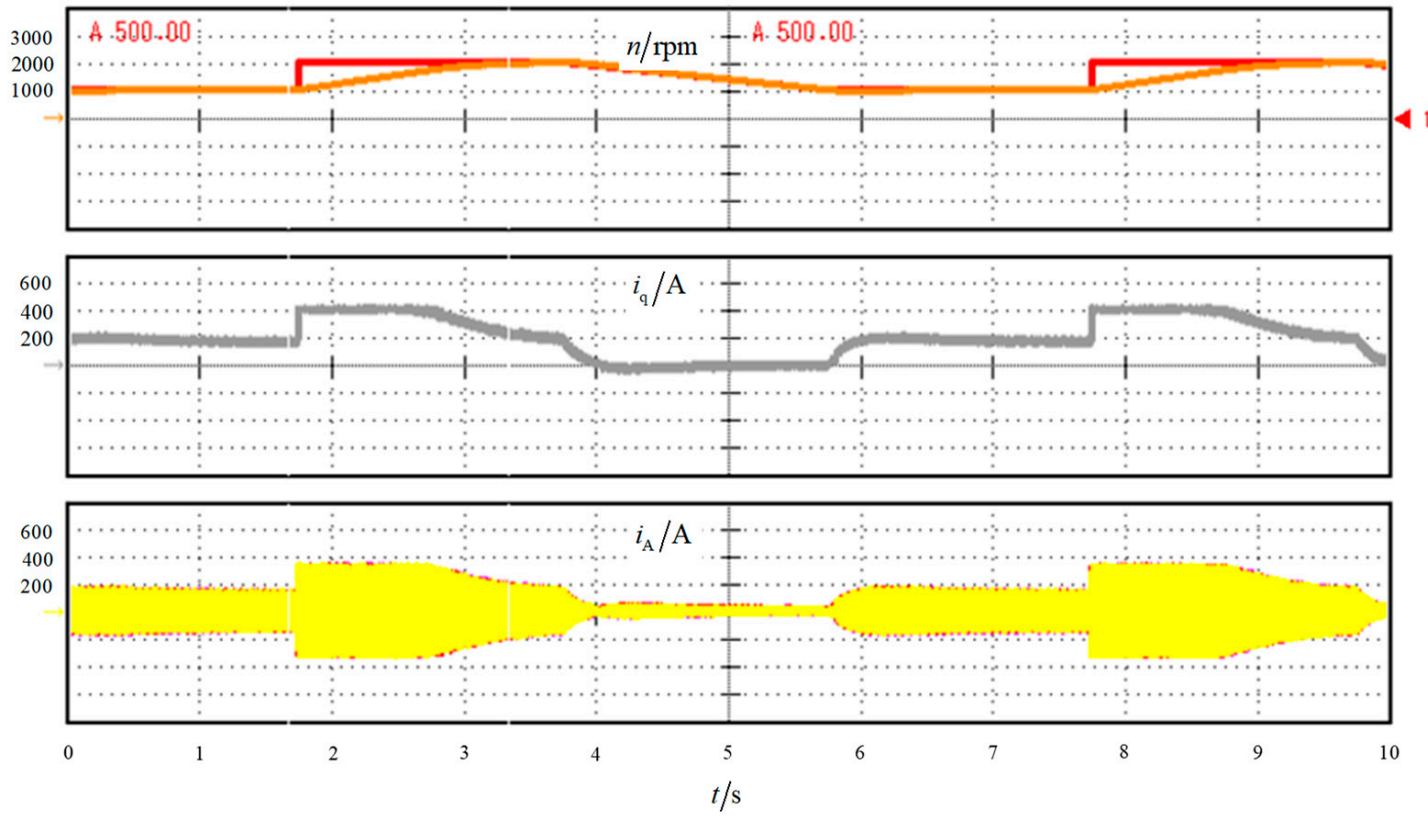

(b)

Figure 12. Motor current: (a) adopting traditional PI regulator and (b) adopting the 2DOF regulator.

The proposed control strategy of the FPMTS was implemented on the new type of shunting locomotive. Figure 14 shows the test run photo of the shunting locomotive dragging eight vehicles. 

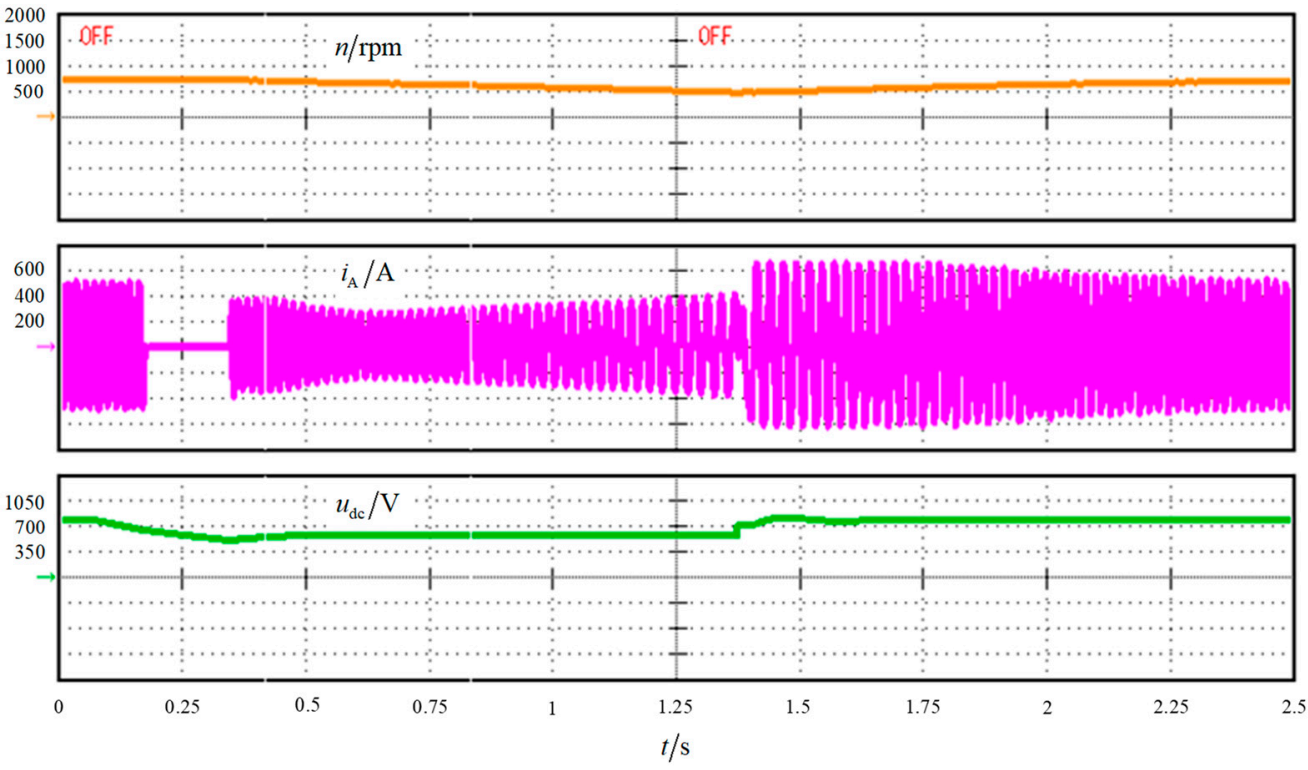

Figure 13. Responses in the restart process on the FPMTS test platform.

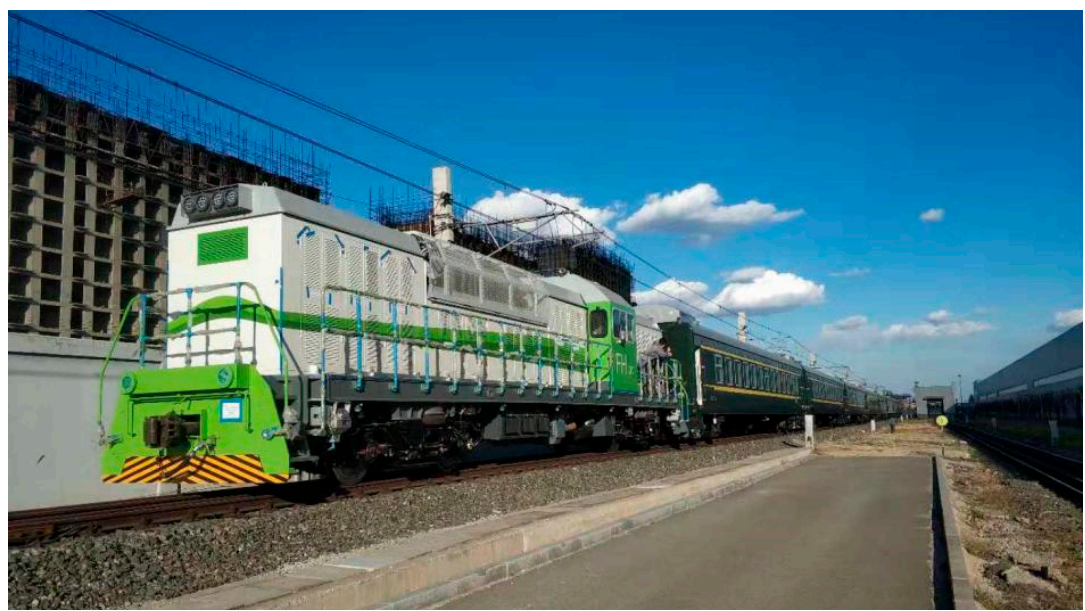

Figure 14. Test run of the diesel shunting locomotive equipped with FPMTS.

\section{Conclusions}

This paper researched and analyzed the permanent magnet transmission system control of diesel railway vehicles. Herein, we proposed that the FPMTS take the PMSM as both its generator and traction motor and it was constructed as a coordinated control strategy between the diesel and permanent magnet traction motor. To further improve the FPMTS performance, the design and implementation of the 2DOF regulator and the standard unit current maximum torque control strategy were investigated. In addition, the wheel slip protection control and fault protection strategy were proposed. The simulation and experimental results validated that the FPMTS and control strategy obtained a satisfying performance. The operation of shunting machine showed that the permanent magnet system was an important solution to improve the performance of diesel railway vehicles, and the study of FPMTS has laid the foundation for the subsequent application of permanent magnet motors in high-power diesel locomotives and high-speed diesel multi-units.

In the future, research should focus on improving the energy utilization efficiency of railway vehicles. Hence, in our follow-up work, we will try to add energy recycling and storage devices to the FPMTS in order to optimize the system control strategy. 
Author Contributions: Conceptualization, L.K. and C.X; methodology, L.K.; software, C.X.; validation, L.K., Y.X., and K.S.; formal analysis, L.K.; investigation, L.K.; writing—original draft preparation, L.K.; writing-review and editing, C.X.; visualization, C.X.; supervision, C.X.; project administration, D.J. All authors have read and agreed to the published version of the manuscript.

Funding: This research was funded by CRRC Tangshan Co., Ltd., grant number R91510.

Data Availability Statement: The data presented in this study are available on request from the corresponding author.

Acknowledgments: The authors would like to thank the anonymous reviewers for their reviews and comments.

Conflicts of Interest: The authors declare no conflict of interest.

\section{References}

1. van der Meulen, D.; Möller, F. Sustainable heavy haul traction energy: A review of systemic issues. Proc. Inst. Mech. Eng. Part F J Rail Rapid Transit 2014, 228, 687-694. [CrossRef]

2. Shiraki, N.; Satou, H.; Arai, S. A hybrid system for diesel railcar series Ki-Ha E200. In Proceedings of the 2010 International Power Electronics Conference (IPEC 2010), Sapporo, Japan, 21-24 June 2010; pp. 2853-2858.

3. Schmid, S.; Ebrahimi, K.; Pezouvanis, A.; Commerell, W. Model-based comparison of hybrid propulsion systems for railway diesel multiple units. Int. J. Rail Transp. 2018, 6, 16-37. [CrossRef]

4. International Union of Railways; International Energy Agency. Railway Handbook 2017; International Energy Agency: Paris, France, 2017.

5. Shamardina, V.N.; Anishchenko, M.V.; Lemeshko, S.M.; Kanunnikov, R.V. Functional efficiency enhancement of diesel-electric locomotive traction system. In Proceedings of the 2017 International Conference on Modern Electrical and Energy Systems (MEES 2017), Kremenchuk, Ukraine, 15-17 November 2017; pp. 20-23.

6. Germishuizen, J.; Jockei, A.; Hoffmann, T.; Teichmann, M.; Lowenstein, L.; Wangelin, F.V. SyntegraTM-Next generation traction drive system, total integration of traction, bogie and braking technology. In Proceedings of the 2006 International Symposium on Power Electronics, Electrical Drives, Automation and Motion(SPEEDAM 2006), Taormina, Italy, 23-26 May 2006; pp. 1073-1077.

7. Binder, A.; Koch, T. Permanent magnet gearless traction drive for German high speed train ICE 3. In Proceedings of the 2001 International Conference on Power Electronics (ICPE 2001), Seoul, Korea, 30 May-3 June 2011; pp. 756-760.

8. Shikata, K.; Kawai, H.; Nomura, H.; Aoki, H.; Fukasawa, S.; Tasaka, Y. PMSM propulsion system for Tokyo Metro. In Proceedings of the 2012 Electrical Systems for Aircraft, Railway and Ship Propulsion (ESARS 2012), Bologna, Italy, 16-18 October 2012.

9. Jianghua, F. Development Overview and Application Challenges of Permanent Magnet Synchronous Traction System for Rail Transit. High Power Convert. Technol. 2012, 3, 1-7.

10. Matsuoka, K. Development trend of the permanent magnet synchronous motor for railway traction. IEEJ Trans. Electr. Electron. Eng. 2007, 2, 154-161. [CrossRef]

11. Ito, T.; Inaba, H.; Kishine, K.; Nakai, M.; Ishikura, K. Method controlling four sets of permanent magnet synchronous motor by one inverter on a railway vehicle. In Proceedings of the 2014 17th International Conference on Electrical Machines and Systems (ICEMS 2014), Hangzhou, China, 22-25 October 2014; pp. 245-249.

12. Roumani, K.; Schmuelling, B. Topology selection for low voltage PMSM for in-wheel direct-drive application. In Proceedings of the 2017 19th International Conference on Electrical Drives and Power Electronics (EDPE 2017), Dubrovnik, Croatia, 4-6 October 2017; pp. 235-241.

13. Sheng, Y.; Zhou, W.; Hong, Z.; Yu, S. Field weakening operation control of permanent magnet synchronous motor for railway vehicles based on maximum electromagnetic torque at full speed. In Proceedings of the 29th Chinese Control Conference, Beijing, China, 29-31 July 2010; pp. 1608-1613.

14. Calleja, C.; López-de-Heredia, A.; Gaztañaga, H.; Aldasoro, L.; Nieva, T. Validation of a modified direct-self-control strategy for PMSM in railway-traction applications. IEEE Trans. Ind. Electron. 2016, 63, 5143-5155. [CrossRef]

15. Zhao, K.; She, J.; Zhang, C.; He, J.; Huang, G.; Liu, J. Robust Closed-loop Torque Control for PMSM of Railway Traction Considering Demagnetization. In Proceedings of the IECON 2019-45th Annual Conference of the IEEE Industrial Electronics Society, Lisbon, Portugal, 14-17 October 2019; pp. 6916-6921.

16. Taniguchi, S.; Yasui, K.; Yuki, K.; Nakazawa, Y.; Onda, S. A Restart Control Method for Position Sensorless PMSM Drive Systems Without Potential Transformer for Railway Vehicle Traction. Electr. Eng. Jpn. 2015, 193, 44-53. [CrossRef]

17. Zhao, S.; Huang, X.; Fang, Y.; Li, J. A control scheme for a High Speed Railway traction system based on high power PMSM. In Proceedings of the 2015 6th International Conference on Power Electronics Systems and Applications (PESA 2015), Hong Kong, China, 15-17 December 2015; pp. 1-8.

18. Zhang, Z.; Ge, X.; Tian, Z.; Zhang, X.; Tang, Q.; Feng, X. A pwm for minimum current harmonic distortion in metro traction pmsm with saliency ratio and load angle constrains. IEEE Trans. Power Electron. 2017, 33, 4498-4511. [CrossRef]

19. Jahns, T.M.; Kliman, G.B.; Neumann, T.W. Interior permanent-magnet synchronous motors for adjustable-speed drives. IEEE Trans. Ind. Appl. 1986, 738-747. [CrossRef] 
20. Kim, H.; Hartwig, J.; Lorenz, R.D. Using on-line parameter estimation to improve efficiency of IPM machine drives. In Proceedings of the 2002 IEEE 33rd Annual IEEE Power Electronics Specialists Conference, Cairns, Australia, 23-27 June 2002; pp. 815-820.

21. Nguyen, Q.K.; Petrich, M.; Roth-Stielow, J. Implementation of the MTPA and MTPV control with online parameter identification for a high speed IPMSM used as traction drive. In Proceedings of the 2014 International Power Electronics Conference (IPEC 2014), Hiroshima, Japan, 18-21 May 2014; pp. 318-323.

22. Li, F.; Xia, C. Inductance Identification Algorithm and Variable-Parameters MTPA Control Strategy for IPMSM Considering Magnetic Circuit Saturation. Diangong Jishu Xuebao/Trans. China Electrotech. Soc. 2017, 32, 136-144. 